\title{
As Origens da Teoria Desenvolvimentista: A Economia Política Empiricamente Baseada e Historicamente Contextualizada de Furtado
}

James Martín Cypher

\begin{abstract}
Resumo: Celso Furtado, um dos criadores da Política Econômica Estruturalista da América Latina, concentrou-se na construção de um projeto nacional viável de desenvolvimento para o Brasil. Um sofisticado defensor de uma mudança estrutural, representou um reformismo orientado para o futuro baseado em análises pragmáticas do subdesenvolvimento - 'a' inerente condição das nações periféricas. O objetivo deste artigo é oferecer uma síntese e uma avaliação de suas contribuições para a política econômica da Economia do Desenvolvimento. A hipótese deste artigo é que a metodologia/posição de análise de Furtado - em particular, (1) sua abordagem dinâmica, historicamente contextualizada, e (2) sua tendência em centrar o desenvolvimento em capacidade tecnológica - merece mais ampla aceitação e maior reconhecimento. Uma hipótese auxiliar é que o trabalho de Furtado é um paralelo ao feito no início do institucionalismo dos Estados Unidos da América (particularmente de Veblen) e, também, que Furtado e seus seguidores perderam a oportunidade de explorar as complementariedades e sinergias que poderiam ter sido forjadas para renovar a perspectiva desenvolvimentista Furtadiana.
\end{abstract}

Palavras-chave: Celso Furtado, Desenvolvimentismo, Estruturalismo, Dependência, Especificidade Histórica, Tecnologia, Trajetória Dependente/ Dependência Histórica.

JEL: B52, E14, N16, 020, 033

Para fontes bibliográficas, a assistência de Carlos Mallorquin é grandemente agradecida. Este artigo éuma versão traduzida para o português do Brasil do artigo "The Origins of Developmentalist Theory: The Empirically-Based, Historically-Contextualized Political Economy of Furtado", publicado na International Journal of Political Economy, v. 43, n. 4, 2014, com a permissão da Taylor \& Francis LLC. Tradução realizada por Nícolas Lazzaretti Berhorst, estudante de Ciências Econômicas na Universidade Federal do Paraná. Bolsista do UFPR Internacionalizar Mais. E-mail: nicberhorst@gmail.com 


\section{The Origins of Developmentalist Theory:The Empirically-Based, Historically-Contextualized Political Economy of Furtado}

Abstract: Celso Furtado, a creator of Latin American Structuralist Political Economy, was riveted upon the construction of a viable national development project for Brazil. As a sophisticated advocate for structural change, he represented forward looking reformism based in a pragmatic analysis of underdevelopment- 'the' lookng reformism based in apragmatic analysis of underdevelopment to offer both a synthesis and an evaluation of his contributions to the political economy of development economics. The hypothesis of this article is that Furtado's methodological/analytical stance-in particular, (1) his dynamic, historically-contextualized, approach and (2) his tendency to center development on technological capacity - merits broader acceptance and greater acclaim. An ancillary hypothesis maintains that while Furtado's work paralleled that of early US institutionalism (particularly that of Veblen), he and his followers have thus far missed an important opportunity to explore the complementarities and synergies that might have been forged to renovate the Furtadian developmentalist perspective.

Keywords: Celso Furtado, Developmentalism, Structuralism, Dependence, Historical Specificity, Technology, Path Dependence

JEL: B52, E14, N16, 020, 033

\section{Introdução}

Celso Furtado (1920-2004) foi, sem sombra de dúvidas, o economista brasileiro mais aclamado. Sua longa carreira profissional foi renomada em vários aspectos. Ainda jovem sua pesquisa foi largamente reproduzida nos países de língua inglesa. ${ }^{1}$ Ele teve a grande sorte de estar na situação ideal para tornar-se o criador e desenvolvedor da Política Econômica Estruturalista da América Latina. Foi selecionado por Raúl Prebisch para conduzir a Divisão de Desenvolvimento Econômico (1950-57) na recém-criada Comissão Econômica para a América Latina das Nações Unidas, em Santiago do Chile (conhecida por CEPAL, ou ECLAC em inglês). Furtado se integrou à CEPAL em 1949, depois de terminar sua tese de Ph.D. na Sorbonne em 1948. Após a experiência de ter como colegas próximos os mais inovadores e influentes economistas da América Latina - e Prebisch como mentor - foi para Cambridge no Reino Unido, onde trabalhou por um ano com eminentes Keynesianos, entre eles o N.

1. Artigo de Furtado "Formação de Capital e Desenvolvimento Econômico" foi publicado pela primeira vez no Brasil em 1951; subsequentemente apareceu em Inglês na International Economic Papers, $\mathrm{N}^{\circ}$ 4, em 1954 (Agarwala e Singh's 1958).
Kaldor. Durante este período terminou seu livro de maior número de citações: A Formação Econômica do Brasil (Furtado 1971), impresso pela primeira vez em 1959 e subsequentemente publicado em inglês como The Economic Growth of Brazil (Furtado 1971). Esta obra permanece, ainda através do séc. XXI, um clássico da análise econômica (Araújo, Macambira e Teixeira, 2009). 1958 retornou para o Brasil para trabalhar como conselheiro econômico e formulador político até 1964. Logo antes de seu exílio no mesmo ano - consequência do golpe militar inteiramente apoiado pelo governo dos Estados Unidos - Furtado buscava uma política viável desenvolvimentista para o extremamente pobre Nordeste do Brasil. Busca que o levou a advogar abertamente pela reforma agrária. Essa posição trouxe o primeiro revés negativo em sua carreira e foi dispensado do cargo de Ministro do Planejamento do Brasil em 1963. A ditadura militar no Brasil teve início em abril de 1964 e terminou em março de 1985. Durante o exílio, Furtado começou uma nova carreira como professor universitário na Université Paris I (1965-80). Como é de se esperar, interrompeu sua pesquisa no projeto de construção de um modelo nacional viável de desenvolvimento para o Brasil e, sem surpresas, mudou o rumo de sua análise drasticamente. Comecou, portanto, a trabalhar com o papel do capital estrangeiro na desnacionalização da base produtiva. Processo este que levou à criação de estruturas de dependência nacional nas nações periféricas. Em 1979 foi possibilitado seu retorno ao Brasil, onde ocupou uma variedade de posiç̃es de estadista sênior e formulador de políticas até o seu falecimento em 2004. Durante este conturbado período ele renovou seu foco confiante e essencial na potencialidade de alcançar - por construção criativa - um projeto viável de desenvolvimento nacional. É interessante notar que $\mathrm{F}$. H. Cardoso - Presidente do Brasil entre 1995-2002, e o criador da teoria de 'desenvolvimento dependente associado' - argumentou que "a confiança de Furtado na habilidade do Estado de planejar e conduzir um processo de desenvolvimento endógeno e independente foi... exagerada" (Cardoso 2005:5).

Na tentativa de encapsular o longo percurso da carreira de Furtado, é importante entender que ele incorporou uma liderança de modo que suas ligações político-econômicas o auxiliaram para avançar com sucesso ao longo de sua sofisticada advocacia pela mudança estrutural. Ele representou um reformismo orientado para o futuro baseado em análises pragmáticas de subdesenvolvimento, que é a condição inerente das nações periféricas (criadas séculos atrás pelo exercício do poder colonial). Esta condição estrutural, conforme se argumentava, não era uma 'fase' mas poderia ser ultrapassada através de planejamento de projetos, capacidade pública e reconstrução institucional.

Ao longo de sua vida Furtado publicou constantemente uma corrente de artigos e livros - número exaustivo de obras que foram recentemente analisadas - principalmente no Brasil (veja, por exemplo, Boianovsky 2008; Corsi e Camargo 2010; Guillén y Vidal 2008; Mallorquin 2005; Tavares 2000). Não obstante, fora do Brasil e na maioria das vezes dentro da América Latina, a figura de Furtado no desenvolvimento foi pouco reconhecida: por exemplo, 
ele foi praticamente esquecido na primeira edição do The New Palgrave: Economic Development, no qual teve seu nome apenas uma vez mencionado em The Origins of Development Economics, e, inacreditavelmente, foi excluído da lista dos Fifty Key Thinkers on Development (Eatwell, Milgate and Newman 1989; Jomo and Reinert 2005; Simon 2006).

O objetivo deste artigo não é adicionar uma dissecação das longas publicações de Furtado; muito menos fazer uma exploração da 'história do pensamento'. Mas sim, oferecer uma síntese e uma avaliação de suas contribuiç̃os para a política econômica da Economia do Desenvolvimento. Este artigo tampouco é um exercício suplementar na historiografia de ideias; é um esforço para localizar os méritos essenciais de Furtado na política econômica - centrados em (1) estruturalismo, (2) contextualização histórica e (3) capacidade tecnológica - os quais possibilitariam uma reformulação pós-neoliberal da política de desenvolvimento. A hipótese deste artigo é que a metodologia/posição de análise de Furtado - em particular sua abordagem dinâmica, historicamente contextualizada, sua tendência em centrar o desenvolvimento em capacidade tecnológica - merece ampla aceitação e maior aclamação. Uma hipótese complementar à esta proposta é que o trabalho de Furtado é um paralelo ao feito no início do institucionalismo dos Estados Unidos da América (particularmente de T. Veblen) e, também, que ele e seus seguidores perderam a oportunidade de explorar as complementariedades e sinergias que poderiam ter sido forjadas para renovar a perspectiva desenvolvimentista Furtadiana. Esse item é analisado na última seção deste artigo.

\section{Situando Furtado: O que é 'Economia'?}

Ao menos no Brasil houve uma tentativa tanto quanto acrítica de delinear a "economia" em três área distintas - Microeconomia, Macroeconomia e Desenvolvimento Econômico - sem prezar pelo fato de que um nível importante de delineação escurece as tensões mútuas e incongruidades incorporadas nesta divisão de três níveis. 2 Por exemplo, tem sido crescentemente evidente, que a cada momento que passa, microeconomistas neoclássicos têm travado uma prolongada guerra contra qualquer existência da tentativa de demarcar a Macroeconomia como um campo separado de análise através da campanha dos 'Microfundamentos da Macroeconomia'. ${ }^{3}$ Enquanto isso, o Desenvolvimento Econômico foi sumariamente dispensado, em um campo separado, por um dos mais celebrados microeconomistas. ${ }^{4}$ Todavia, esse ataque reverberou

2. Ver (Bresser-Pereira 2007: 14-17)

3. Para uma análise desta trajetória que foca em Desenvolvimento Econômico, ver (Herrrera 2006); para uma vasta e destrutiva crítica desta trajetória, agora conectada com o erguimento da hegemonia neoliberal na análise econômica ortodoxa, ver (Mirowski 2013)

4. Ver, Krugman, P. 1995. "The fall and rise of development economics" em Development, Geography and Economic Theory. Cambridge: MIT Press: 1-30. Este capítulo é amplamente difundido no curso de desenvolvimento de graduação em universidades norte-americanas. dentro e fora da Economia do Desenvolvimento. Aparentemente, foi suficiente que um aclamado economista do comércio (posteriormente ao recebimento de um prêmio de Ciências Econômicas do Banco da Suécia) tenha acusado os principais economistas desenvolvimentistas de oferecer nada mais que apresentações retóricas, e desse modo, de criar uma "nova escola do desenvolvimento [baseada] em metáforas sugeridas, realismo institucional, raciocínio interdisciplinar, e uma atitude relaxada frente a consistência interna" (Krugman 1995: 23) ${ }^{5}$. Segundo este autor, a "teoria do desenvolvimento foi abandonada", porque "os artigos clássicos do campo começaram a aparecer... simplesmente incompreensíveis" (Krugman 1995: 23). Alegou, ainda, que "Desenvolvimento Econômico foi um estilo arcaico até mesmo para seu próprio tempo" (Krugman 1995: 24). Ancorando esta polêmica, foi a sua revelação da natureza transgressiva imperdoável dos "pioneiros do desenvolvimento' (incluindo Albert Hirschman, Arthur Lewis, Gunnar Myrdal, e Paul Rosenstein-Rodan) porque eles falharam ao construir modelos. Isso coloca todo o esforço de economistas desenvolvimentistas além dos limites da "Economia" já que "a Teoria Econômica é essencialmente uma criação de modelos" (Krugman 1995: 27). Ironicamente, a data da publicação destas 'observações' coincide com a crítica de Heilbroner e Milberg sobre a economia ortodoxa, a qual enfatizou a "extraordinária indiferença" dos praticantes dentro do paradigma dominante, que não tiveram qualquer preocupação em encontrar conexões entre a realidade e sua mania-de-criação-de-modelos-teóricos (Heilbroner and Milberg 1995: 3-4). Neste sentido, estes autores encontraram evidência de uma espiral analítica descendente profunda que tinha deixado a corrente principal do lado de fora das longas correntes históricas que tinham definido a economia como um campo da análise. Em contrapartida, argumentaram que economistas contemporâneos neoclássicos classificaram todos os problemas, que eles foram incapazes de analisar com seus modelos matemáticos, de 'problemas não-econômicos' (Heilbroner and Milberg 1995: 7).

As tendências desafiadas por Krugman, as quais Heilbroner e Milberg deploraram, ganharam ímpeto durante a década de 90, convergindo com a criação e propagação do modelo EGDE (Equilíbrio Geral Dinâmico Estocástico), que se tornou a abordagem dominante em universidades de elite para toda a análise económica, incluindo a teoria macroeconômica de crescimento (que incorporou o termo "desenvolvimento"). Segue uma recente descrição oferecida pela Casa do Comitê Representativo de Ciência e Tecnologia dos Estados Unidos: 5. A aula original de Krugman sobre Ohlin, ministrada na Stockholm School of Economics no Outono de 1992
incluiu este e um número de similares afirmações que foram erradicadas da versão publicada em 1995. A versão original está disponível no link: http://web.mit.edu/krugman/www/dishpan.html
onch 
'Geral' indica... todos os mercados na economia. 'Equilíbrio' [significa] que a oferta e a demanda se equalizam... e que a competição lidera em mercado que não são perturbados por déficits... ou desemprego... 'Estocástico' corresponde a... aleatoriedade gerível... que permite eventos inesperados... mas assume que os agentes do modelo podem atribuir uma probabilidade matemática correta para [todos] os eventos.

Os agentes... são dotados com... clarividência. Imortais, eles veem até o fim dos tempos e sabem de tudo que possa possivelmente acontecer...; suas decisões são sempre instantâneas e nunca errôneas... todos... indivíduos ou empresas possuem necessidades idênticas e... gostos, que como 'optimizadores', eles buscam com ilimitado interesse próprio e completo conhecimento... (citado por Mirowski 2013: 276).

Confrontados com as críticas ensurdecedoras deste modelo e de suas recém formuladas abordagens de fundamentos micro para macro, somado ao cenário da Grande Recessão de 2007, os praticantes ortodoxos procuraram se esquivar e ignorar suas críticas, agarrando-se sempre mais à sua consagrada abordagem do modelo EGDE (Mirowksi 2013: 276-294).

Na virada do milênio, o enfoque Furtadiano sobre desenvolvimento (e de qualquer outro que não tenha sido derivada dos pressupostos do modelo EGDE) foi definitivamente julgado 'não-econômico' em sua totalidade, assim como 'incompreensível'. Contudo, uma modesta corrente contrária persistiu até certo ponto, algumas vezes conhecida vagamente como 'heterodoxia', incluindo o institucionalismo Vebleniano e o 'neo-schumpeterianismo', que abordou o crescimento e o desenvolvimento como uma análise econômica "evolutiva". Aqui nós encontramos os praticantes remanescentes do desenvolvimento econômico que não são citados pelos discursos neoclássicos (como exibidos pela denúncia de Krugman e pela sinopse do modelo EGDE supracitada) que construíram e consolidaram o que pode ser nomeado Micro-fundações 'Monoeconomia'. Em contraste, no Brasil, especificamente a partir do fim de 2002 quando o poder do Estado mudou para forças progressivas-nacionalistas, uma alternativa emergente heterodoxa sobre a política pública encorajou a ressurreição do desenvolvimentismo Furtadiano. Agora chamado de 'novo' ou ‘novo-desenvolvimentismo’ (Bresser-Pereira 2011; Cypher 2014).

\section{Estruturalismo segundo Furtado}

Furtado recebeu seu doutorado na Sorbonne sob a orientação de renomados historiadores economistas estruturalistas franceses, incluindo especialmente F. Perroux:
Perroux (1939) definiu economia estrutural como a ciência das relações características de um sistema econômico situado no tempo e espaço. No centro da abordagem de Perroux está a idéia de que, além da 'dada' teoria neoclássica (preferências, recursos e tecnologia), a análise de instituições e estruturas ao longo do tempo tem de estar no coração da análise econômica. Uma contribuição inovadora importante de Perroux tem a ver com sua teoria de dominação, que é central à concepção [da CEPAL] de sistemas econômicos: ao invés de ser constituído por relações entre [entidades] iguais, o mundo econômico é conceituado em termos de ocultas relações explícitas de 'força', 'poder' e 'restrições' entre entidades dominantes e dominadas. (Blankenvurg, Palmas and Tregenna 2008: 3).

Mas como notou Furtado, o estruturalismo da CEPAL não era diretamente baseado em Perroux ou em qualquer outro estruturalista francês. Para ele este estruturalismo constituía a "abordagem histórica-estrutural" trazendo junto a "noção de estrutura como um jogo de relações estáveis descritas por um modelo, e o conceito de processo como uma sequência causal de fatos em um tempo histórico" (Boianovsky 2014: 4). O método consistiu em examinar o todo para entender as partes, no qual o ‘todo' consiste de uma combinação de partes inter-relacionadas que são interconectadas reciprocamente.

Fundou-se parcialmente em uma análise dinâmica do que então foi (e agora) considerado "parâmetros não-econômicos em modelos macroeconômicos" - como a estrutura agrária, atraso tecnológico, subemprego "o controle de firmas, a composição da força de trabalho e assim por diante" (Furtado 1987: 209-10). A questão mais profunda aqui tem a ver com a pergunta: quem ocupa a posição de hegemonia ideológica para delimitar o campo de estudo, arbitrariamente e aprioristicamente, condenando assuntos como 'não-econômicos', que não podem ser facilmente dobrados em limitados modelos baseados em pressupostos de um pais desenvolvido, sob condições de competitividade levadas por tendências harmoniosas, estáveis, de equilíbrio de mercado e com 'perfeito-conhecimento' sob condições de metodologia individual?

Furtado, tanto por causa do seu treinamento na França como por causa da sua emersão imediata na CEPAL, desenvolveu as suas principais ideias estruturalistas nestes dois ambientes únicos que não se tinham contaminado pelas condiç̃es em espiral descendentes que varreram o campo e estreitaram os limites 'da economia' nos anos 1930 e anos 1940. O mais importante nesta descida foi a participação ávida de L. Robbins que procurou, como diretor da influente London School of Economics de 1929, definir o 'domínio' das 'Ciências Econômicas'. Em 1932 Robbins publicou a primeira edição do An Essay on the Nature and Significance of Economic Science, cujo objetivo era garantir uma revisão da história para obliterar a corrente que A. Marshal defendeu por seus métodos e análises da German Historical School (Hodgson 2001: 95-112). Robbins argumentou, em uma frase que se tornara famosa, 
que 'Economia' poderia apenas ser considerada como alocação de recursos escassos (sob condições de pleno emprego e capacidade) para fins específicos. Esta 'definição' dos limites de análise foi feita com o intuito de se poder aplicar para todos os campos socioeconômicos, sem consideração de tempo ou espaço. "Robbins via Economia como a exploração a priori de deduções dos axiomas da escolha racional" (Hodgeson 2001: 209). "Economia não deveria mais contar institucionalmente ou historicamente com um domínio específico de análise” (Hodgson 2001: 207).

Robbins buscou e eventualmente alcançou a hegemonia intelectual para os 'teóricos gerais' os quais não “... reconhecem o problema da especificidade histórica, porque eles acreditam que a economia pode prosseguir inteiramente com base em premissas universais e historicamente não especificadas" (Hodgson 2001: 28). Robbins, mais tarde ajudou a formar a influente Sociedade Mont Pèlerin em 1947, lá estabelece as bases para uma doutrina que mais tarde seria conhecida como neoliberalismo (Mirowski 2013: 6-8). Em 1932 publicou um paper que, como um rolo compressor, rapidamente deslegitimou todas as formas de análise econômica, salvo aquelas caracterizadas por um restrito e estéril exercício dedutivo que corroborava com o neoclassicismo e Teoria Austríaca. Em parte, foi influenciado pelo desejo de J. Schumpeter de fazer as acusações mais abusivas (incluindo incompetência) contra a German Historical School e Veblen (Shumpeter 1930). Após um curto espaço de tempo, em 1947, P. Samuelson facilitou a consolidação da posição da hegemonia ideológica a formulação de Robbin, ao definir seus estreitos limites sobre 'Economia' em seu notável texto introdutório.

Enquanto a cruzada entre Robbins/Schumpeter/Samuelson eliminava todas as outras formulações sobre o domínio da Economia, a Escola Estruturalista da América Latina (envolta por seu ambiente distinto e distante) rapidamente se materializou. Para eles, a problemática' do 'desenvolvimento' era vista como um novo campo, que demandava uma forma separada de análise, assim como Furtado frequentemente defendia. Dado (1) a isolação relativa da CEPAL de suas principais correntes metodológicas de Economias Anglo-saxônicas, (2) sua incomparável independência institucional como o primeiro centro de pesquisa da ONU estabelecido no Sul do Mundo e (3) a irrelevância do 'mainstream' econômico para uma análise heterodoxa de estruturas econômicas subdesenvolvidas - conhecida mesmo por muitos economistas 'mainstream' que ajudaram a criar a Economia do Desenvolvimento após a WW II - fizeram com que Furtado e seus colegas em Santiago pudessem forjar livremente e desimpedidamente (por enquanto) com suas próprias pesquisas baseadas em suas explicações estruturalistas.

\section{Desenvolvimento Autêntico ou 'Dependência'?}

Dado que a relevante matriz de forças e fatores condicionantes a serem determinados e analisados poderiam ser (esquematicamente) divididos entre elementos endógenos/exógenos aos economistas da CEPAL, os quais, particularmente Furtado durante seu exílio, apresentaram sua versão 'estruturalista' da teoria sobre a 'dependência'. Esta era superficialmente similar, contudo significativamente distinta das subsequentes versões teóricas cheias de ideologia, completamente desacreditadas, propostas por A. G. Frank, ou por aqueles seguidores da abordagem do World Systems. (Blankenburg, Palma and Tregenna 2008; Cypher 1979; Palma 1978). O objetivo do trabalho da CEPAL não era de abandonar a pesquisa da formação nacional subdesenvolvida ou de rejeitar sua atividade em termos de causalidade primária, mas sim de adotar uma "abordagem inclusiva.... A fim de aumentar nosso conhecimento sobre as conexões entre relações externas e formas internas de domínio social" (Furtado 1987: 210). Ao investigar aspectos de 'dependência estrutural' novas forças e fatores - incluindo o Estado e Firmas Multinacionais - foram trazidos para o primeiro plano de análise. Não obstante, os Economistas cepalinos inadequadamente teorizaram o Estado, e assim, falharam em não aproveitar a oportunidade (Alavi 1982; Cypher 1990).

O nome de Furtado tem sido constantemente associado com "dependência”, mas sua abordagem nesse tema possui nada em comum como a linha de pensamento sobre a dependência, a qual argumenta que o desenvolvimento autônomo seria impossível. Furtado argumentou que "a reestruturação que sobressai o subdesenvolvimento sustenta-se uma ordem mais compreensiva do que a compatível pelos mercados, e tal ordem é possível apenas através de planejamento" (Furtado 1987: 225, itálico adicionado). O tal 'planejamento' incluiria diversificação de exportações, como foi feito pelo Japão através de seu Ministério de Comércio Internacional e Indústria (Furtado 1987: 224). Ao rejeitar a "Ortodoxia Marxista", o planejamento seria parcial e limitado já que somente "certas decisões poderão ser centralizadas vantajosamente" - tal como a dispersão geográfica da estrutura industrial ou "aumentar a importância relativa da indústria de bens de capital” (Furtado 1970: 193194). Em resumo, 'dependência' externa é um elemento chave da estrutura do subdesenvolvimento, mas isso não significa necessariamente consignar nações a um estado de degradação perpétua, especialmente porque o estado é potencialmente capaz de aproveitar o excedente econômico para promover políticas de redistribuição de renda e "desenvolvimento autêntico" (veja Figura 1 abaixo) através de um processo consecutivo de "desestruturação social" (Furtado 1987: 224-225). 
CYPHER, J.M. As Origens da teoria desenvolvimentista: A economia política ...

FIGURA 1: PRÉ-REQUISITOS PARA O "DESENVOLVIMENTO AUTÊNTICO"

-"Para alcançar uma alta taxa de desenvolvimento econômico, em sintonia com critérios sociais, faz-se necessário mudanças importantes em nossa estrutura básica"

•"[nós devemos] criar condições para uma reforma rápida e efetiva na arcaica estrutura agrária do País"

-"Nós devemos trilhar firmemente o caminho para uma mudança constitucional que possa permitir a reforma agrária e uma mudança radical na administração pública do sistema fiscal e da estrutura bancária."

•"Nós devemos subordinar as ações do Estado em uma definição clara dos objetivos econômicos e do desenvolvimento social."

•"Nós devemos ter base jurídica legal para subordinar as ações do capital estrangeiro e direcioná-lo para o desenvolvimento econômico e para os requerimentos da independência política."

- "E a cima de tudo, nós devemos ter um plano econômico e social de desenvolvimento compatível com nossas próprias possibilidades e em conformidade com os desejos do nosso povo."

Fonte: Furtado 1963: 534-535

A visão estruturalista apresentada por Furtado tende a priorizar a formação nacional. Mas ela requer entendimento da América Latina e de que suas "realidades sociais trazem peculiaridades cujas propriedades devem ser conhecidas se quisermos entender o funcionamento do sistema econômico" (Furtado 1970: 72). Já que a formação social da América Latina foi criada pela colonização, as estruturas econômicas foram parcialmente construídas com a preferência das demandas impostas. Oportunidades foram criadas com foco na produção e comércio colonial. Em paralelo com a estrutura de comércio urbano influenciada pelo exterior, Furtado enfatizou o papel autônomo da elite latifundiária e o emergente aparelho do Estado, criando então a tripartite do poder onde os fatores 'externo'/'interno' misturaram-se, tornando-se co-determinados e rendendo mudo as supostas tensões dicotômicas de 'externo'/'interno'. (Furtado 1970: 71-109).

Furtado segregou seus pensamentos sobre o desenvolvimento em um modelo de duas estruturas. A primeira sendo aquela de 'estrutura subdesenvolvida simples' ou Economia Híbrida (condição A na Figura 2 abaixo), a qual poderia se desenvolver em uma estrutura com três setores entrando em uma etapa evolutiva e avançada, permanecendo, ainda, em condições de subdesenvolvimento (condição B na Figura 2 abaixo) (Furtado 1964: 129-138). Feita a nítida
CYPHER, J.M. As Origens da teoria desenvolvimentista: A economia política ...

distinção entre estrutura (forma) e processo (casualidade) ele admoestou os estruturalistas que falharam em notar o importante papel dos fatores qualitativos: "Ao confinar-se no plano da descrição morfológica e excluir a noção de causalidade, a abordagem estrutural diminui o horizonte cognitivo" (Furtado 1983: 182, itálico adicionado). A criatividade humana pode ser aproveitada para mobilizar as capacidades inovadoras, forçando descontinuidade estrutural, transcendendo as barreiras do subdesenvolvimento (como modelado na Figura 2), e abrindo o caminho para o "desenvolvimento autêntico '. A Figura 2 oferece detalhes sobre a célebre definição de subdesenvolvimento Furtadiana: "um processo especial causado pela penetração de corporações capitalistas em estruturas arcaicas" (Furtado 1964: 138, itálico adicionado).

FIGURA 2: O MODELO FURTADIANO DE DUAS ESTRUTURAS DE SUBDESENVOLVIMENTO
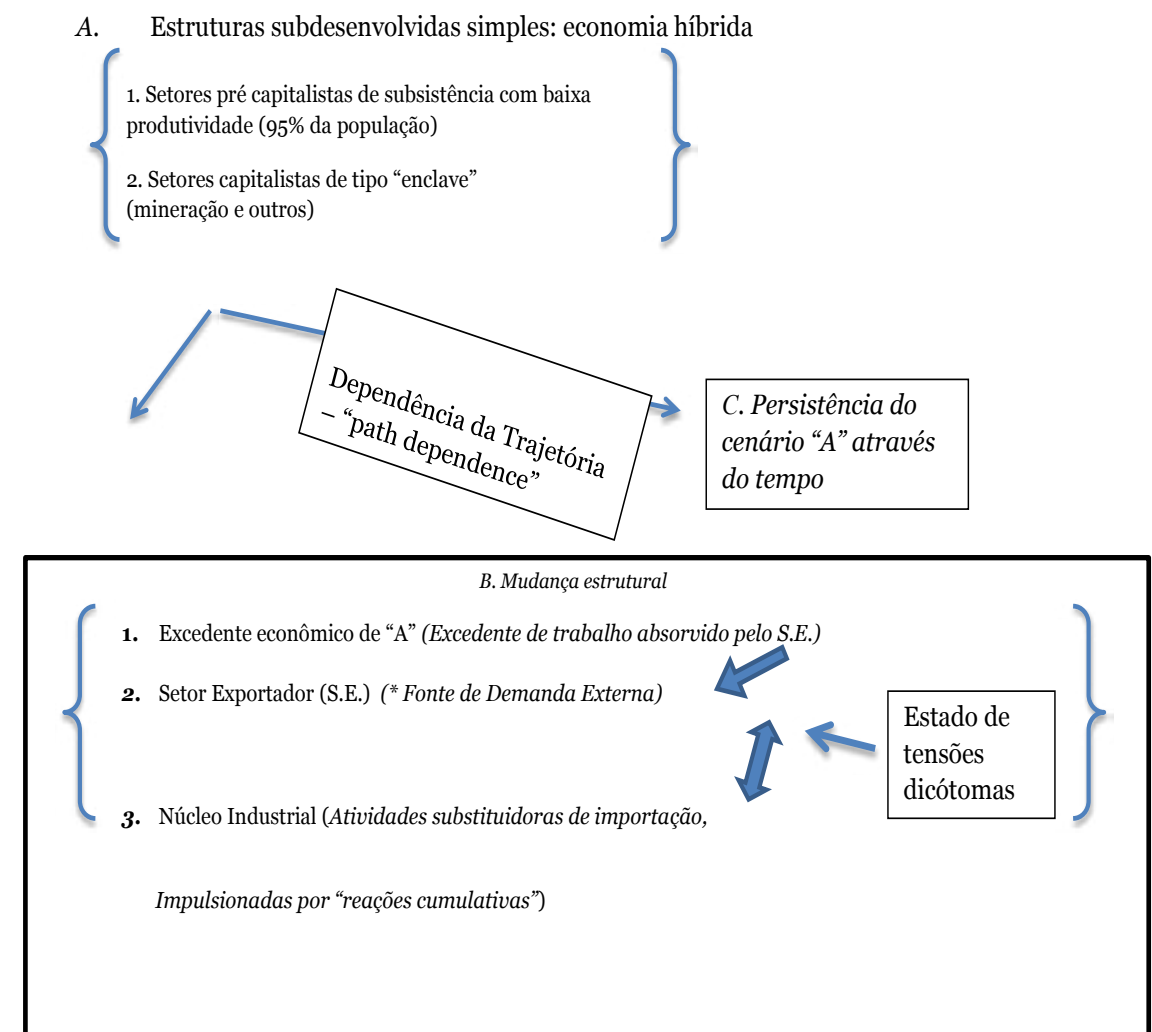

Fonte: Ilustração cunhada pelo Autor e sumário de (Furtado 1964: 129-138) *Agora com efeitos multiplicadores internos

Revista de Economia, v. 40, n. 3 (ano 38), p. 7-27, set/dez. 2014. Editora UFPR 
Ao longo do tempo, Furtado oscilou em sua trajetória histórica sobre seu modelo de duas estruturas. Às vezes detinha-se com uma mal formulada perspectiva de estagnação sobre na etapa evolutiva e avançada, que ainda permanecendo em condições de subdesenvolvimento, de sua modelo de três setores. Em outras vezes, encontrava seu ancoramento essencial de 'reformista progressivo' e mantinha o que - através de um Estado ativo e planejamento estratégico (que seria hoje sem dúvidas nomeado de 'política industrial') sua estrutura de 'maior grau' poderia encontrar um caminho proveitoso para o desenvolvimento autônomo (Furtado 1963; 1964; 129-138; 1970: 83-108 1987). Qualquer modo, ele não afirmou que haveria necessariamente qualquer movimento deliberado de A para B.

A análise da condição 'A' foi, sem sombra de dúvidas, a maior conquista de Furtado. A interpretação completa está no livro Formação Econômica do Brasil (Furtado 1971). Este livro foi um exemplo de contextualização histórica e especificidade, que trouxe à vida a observação feita por Sombart de que: "Não existe economia no abstrato, mas, sim, uma vida econômica particularmente constituída e historicamente distinguível" (Sombart 1930: 196). Aqui Furtado apresentou uma análise profunda da estrutura de pode tripartido mencionado acima e a vantagem de exploração de uma minúscula elite arcaica a quem pertence virtualmente todas as terras. Como visto na Figura 2, neste 'modelo' apenas $5 \%$ da força de trabalho é oriunda dos setores de mineração e plantação - ainda que sejam estes setores que tiveram poder de controle sobre a colônia e que deles foram extraídos uma enorme parte do excedente econômico nacional. Seguindo a teoria de vantagem comparativas, uma Economia Híbrida definha em uma armadilha de baixos recursos, baixa renda e baixa produtividade. Isto não é um estágio histórico, é uma condução estrutural.

Contudo, nações não devem dar-se como perdidas. Conhecedor da hipótese de Prebisch-Singer, Furtado argumentou que os preços descendentes de commodities não são necessariamente um destino. Esforços de protoindustrialização poderiam ser a solucão - particularmente acompanhadas de políticas públicas aptas - quando (1) os preços da commodity estejam altos e (2) exportações são diversificadas sob (3) novos contratos de posse de terra menos concentrados. Aqui os passos iniciais foram possibilitados para uma mudança estrutural quando os comerciantes, donos de terra e instituições financeiras iniciaram um espontâneo processo de substituição de importações fortalecido por políticas públicas que o viabilizaram. Como foi o caso do Brasil antes da Grande Depressão dos anos 30 (Font 2010; Topik 1987).

No Brasil o processo de mudança estrutural foi finalmente consolidado - devido ao empurrão recebido pela Grande Depressão - e direcionou a política econômica completamente para crescimento do mercado interno. Através de um processo de industrialização que foi dirigido pelo Estado a partir dos ano 30, passou através do período da Ditadura Militar, e emergiu-se nos anos 80 como uma nova estrutura político-econômica. Esta forneceu ao Furtado o nascimento de seu segundo 'modelo', o de estrutura com 3 setores, entretanto, permanecendo ainda à condições de subdesenvolvimento, mas agora com capacidades distintas e mais avançadas: aqui Furtado utilizou abertamente o modelo de excedente de mão-de-obra rural de Lewis, argumentando que o setor de subsistência pré-capitalista proporcionou um vasto, lentamente esgotado, conjunto da força de trabalho barata que poderia ser deslocado para setores industriais do comércio em expansão. Com esta alteração o setor de comércio foi substancialmente distinto daquela da 'economia colonial', pois os rendimentos obtidos por este setor são, ao menos parcialmente, reinvestidos em distintas atividades econômicas - incluindo atividades nascentes relacionadas ao setor de comércio, incluindo manufaturas de exportação, assim como substituição de importações ou setores industriais 'estratégicos' suportados através de promoção do Estado. Isto significa que o setor de comércio se tornou uma fonte dinâmica ao promover a mudança interna; fomentando seu crescimento através dos efeitos do multiplicador de spillovers que surgiram ao reinvestir seus ganhos na economia nacional. Como a grande força de trabalho foi aproveitada, o setor industrial emergente e o setor comercial ainda em expansão competiriam por posições efetivas de trabalho dentro da política econômica nacional. Portanto, um estado de 'tensão dicotômica' entre dois setores dinâmicos definiria o novo modelo e, possivelmente, transmitiriam forças centrífugas.

Furtado vacilou ao explicar o peso necessário às forças entrópicas e contradições endógenas dentro de seu segundo modelo. Particularmente após o golpe militar que o enviou ao exílio, Furtado avançou em várias e não convincentes hipóteses de estagnação. $\mathrm{O}$ fato de suas hipóteses terem sido publicadas aproximadamente ao mesmo período do chamado "Milagre Brasileiro", quando a média de crescimento do PIB era de 10,1\% entre 1968-1976, fez com que sua hipótese sobre estagnação perdesse ainda mais credibilidade (Baer 2001: 462).

Furtado ressaltou que o modelo de 3 setores "não trouxe mudança alguma nas condições de vida de três quartos da população do país. Seu maior aspecto tem sido a concentração de renda - socialmente e geograficamente" (Furtado 1963: 527). Argumentou, ainda:

O modelo providenciou ao país os instrumentos para fazer decisões, dada a habilidade de exercer escolha e, ao fazer as pessoas conscientes de seus destinos, os colocou como responsáveis por suas próprias falhas. A causa-raiz do presente estado de mal-estar no Brasil é essa simples verdade: nós sabemos aonde estão os erros em nosso desenvolvimento e nós sabemos que cabe ao nosso poder erradicá-los ou minimizá-los. (Furtado 1963: 527-28, itálico adicionado). 


\section{Ciência, Tecnologia e Desenvolvimento}

Por volta de 1987 Furtado afirmou que o sucesso de "alguns países do Sudoeste Asiático" que seguiram o modelo de planejamento estatal do Japão encontraram "uma nova forma de incorporação no mundo do comércio que estimularia o progresso tecnológico" através de "uma deliberada criação de vantagens comparativas em setores com uma demanda externa elástica” (Furtado 1987: 224-225). Isso ocorreu através de uma adoção de planejamento para facilitar "uma ordem mais coerente e abrangente do que aquela suportada pelos mercados" e por uma política industrial para engajar em "uma reestruturação necessária para eliminar o subdesenvolvimento" (Furtado 1987: 225). Mesmo com sua discussão sobre uma longa lista de forças entrópicas que destruíram o potencial brasileiro para se sobrepor sobre as barreiras do protótipo de "Estágio Superior de Subdesenvolvimento", Furtado defendeu que há exemplos anteriores de transformações políticas e socioeconômicas que ocorreram em outras nações "depois de um longo período de imobilidade" (Furtado 1987: 227).

Para atingir tal transformação, nações subdesenvolvidas teriam que alcançar a dura realidade do século XIX - "quando a ciência se tornou um instrumento de privilégio para acumulação" (Furtado 1983: 160). Para Furtado, que levantou o tema mais do que qualquer erudito da CEPAL, tecnologia é "a aplicação de conhecimento científico" e foi o único meio capaz de "estruturar o processo de produção em termos de critérios da racionalidade instrumental”, o que apó seria "a essência da prática social" necessária para que uma nação confronte as estruturas do subdesenvolvimento. (Furtado 1983: 165-167). Como pode ser facilmente compreendido a partir dos elementos apresentados na Figura 2, a produção em cada setor nos dois modelos estruturalistas de Furtado requer sua própria margem de capacidade tecnológica, com uma falta de correspondência entre eles. Além disso, forças endógenas de dinamismo, decorrentes da obtenção desta mudança tecnológica - especialmente na Economia Híbrida - são completamente ausentes ou muito truncadas. Aqui um essencial e fundamental conceito: a característica decisiva de uma nação subdesenvolvida, em relação com a então chamada "desenvolvida" é, segundo Furtado, a "heterogeneidade tecnológica" (Boianovsky 2008: 5).

\section{Institucionalismo vs. Estruturalismo de Furtado}

A ideia de que há profundas similitudes e pontos congruentes entre a abordagem estruturalista da CEPAL com aquela que dos institucionalistas norte-americanos, tem sido trabalhada, particularmente por James Street e Osvaldo Sunkel (Street 1967, 1987; Sunkel 1990). Curiosamente, Furtado rejeitou categoricamente esta linha de análise e ironicamente apontou que enquanto ele escreveu um livro concebido para observar a dimensão de ideias que "sucederam em 'explicar' o crescimento econômico"; “...os institucionalistas norte-americanos foram excluídos, pois não apresentaram uma interpretação sistemática do processo de crescimento econômico" (Furtado 1964: viii). Surpreendentemente, Furtado não utilizou tais ríspidas palavras contra Solow (Boianovsky 2008: 21-23) mesmo que uma crítica de qualidade desarmou, categoricamente, o famoso modelo de crescimento de Solow na seguinte maneira:

Expansão continua ocorre no sistema neoclássico apenas se assumido que há um aumento autônomo na oferta de fatores, que consiste na mão-de-obra, e mudanças autônomas em tecnologia, ambos os quais são inexplicados. A este respeito, se a expansão contínua ocorrer, seria por razões que não poderiam ser encontradas dentro da teoria e, portanto, não existe teoria de crescimento alguma (Harris 1975: 330).

Em contraste, disse Furtado:

O processo de desenvolvimento consiste em novas combinações de fatores já existentes ou a introdução de inovações tecnológicas. ...[Nós] podemos considerar que são totalmente desenvolvidas, em um dado momento, aquelas regiões as quais, em condições de pleno emprego de fatores, é possível aumentar a produtividade ao apenas introduzir inovações tecnológicas. Essa visão não é irrealista... (Furtado 1964: 61, itálico adicionado)

Aqui Furtado parece resumir o modelo de Solow, mas sem o mencionar e, também, sem criticar. Ainda que, o modelo de Solow, e outros modelos de crescimento neoclássicos em geral, são baseados em suposições fantásticas (pleno emprego, equilíbrio constante, competição perfeita, retornos constantes, etc.) e só 'funcionam', pois, os componentes críticos de um sistema econômico real são completamente deixados de lado. De qualquer maneira, o modelo de Solow, quando aplicado em nações avançadas, amiúde explicaria menos da metade do processo evolutivo em termos de fatores de crescimento (capital e trabalho), e (heroicamente, mas erroneamente) deixa de lado o restante para; (1) mudanças técnicas (concepto que foi deixada indefinida) ou (2) 'ignorância'. Seria marcadamente contraditório que Furtado decidiu conceder aceitação a teoria de crescimento neoclássica, ao mesmo tempo desprezando o institucionalismo norte-americano.

Institucionalistas foram rápidos em perceber e rejeitar o argumento de Furtado (Junker 1967). Junker notou, na primeira edição da primeira revista acadêmica 'heterodoxa' pós-guerra a aparecer nos Estados Unidos da América, que Joan Robinson (a quem Furtado conheceu durante seu período em Cambridge 1957/58) acreditava que o institucionalismo norte-americano era extremamente promissor em responder os questionamentos levantados 
por Furtado (Robinson 1962: 105-110). Rejeitando a teoria ortodoxa sobre a questão crucial de "O que governa a taxa geral de acumulação de capital?" Robinson notou: "Há uma teoria menos conhecida que parece ser mais promissora. Ela é apresentada por um discípulo de Veblen, Professor C. E. Ayres" (Junker 1967: 25-26). Ayres escreveu um importante trabalho, The Theory of Economic Progress (1944), feito em linha com a análise pioneira de Veblen - o papel crucial das instituiçoes e tecnologia como determinantes em um processo de crescimento econômico. Uma leitura cuidadosa de Veblen demonstra sua antecipação e presciente formulação de uma gama de questões fundamentais relevantes tanto para o crescimento quanto para 0 desenvolvimento econômico (Cypher 2009, 2012). Caiu, então, nas mãos de Ayres, Junker, Street entre outros a carregar os insights originais e hipóteses promissoras desenvolvidas por Veblen.

Street publicou na mesma edição do novo jornal institucionalista "The Latin American 'Structuralists' and the Instutionalists: Convergence in Development Theory" (Os 'Estruturalistas' e Institucionalistas da América Latina: Convergência na Teoria Desenvolvimentista) (Street 1967). Aqui ele demonstrou que os Estruturalistas foram desconsiderados pelo mainstream econômico pelas mesmas razões - eles tiveram a audácia de discordar dos postulados da teoria neoclássica. Street encontrou muito mérito em vários trabalhos estruturalistas, particularmente de Pinto, Prebisch e Sunkel, mas tomou pouquíssimo conhecimento de Furtado. Ironicamente, juntamente com muitos elogios Street concluiu que a maior fraqueza do Estruturalismo da América Latina era que “...parece[u] ter tomado conhecimento, apenas recentemente, do significante potencial da mudança tecnológica no processo de desenvolvimento doméstico" já que Prebisch e outros assumiram que "inovação tecnológica é algo exclusivamente do centro" (Street 1967: 56). Em geral, a observação de Prebisch de que no século XIX a América Latina tenha caído sob o controle de "uma classe social que não possui qualquer conhecimento sobre uma cultura baseada em tecnologia" era ao mesmo tempo correto e resistentemente presciente (Street 1987: 57). Como observado na seção anterior, Furtado foi o Cepalista mais sábio em relação ao tema do a importância da tecnologia e do legado cultural disfuncional descientífico da 'economia colonial': Uma condição prévia que se mantivessem em vigor no Brasil até o fim do século XIX, e nos demais países da América Latina ainda no século XX (Furtado 1971: 41; 1964: 133).

O institucionalismo evolucionário teve pouca dificuldade em transferir a terminologia 'estruturalismo' dos economistas da CEPAL. "Estruturas" são sem dúvida 'instituições', " mas a "literatura estruturalista revela uma assustadora inocência no relacionamento com o defendido no institucionalismo norte-americano" (Street: 1967: 55). No ponto crucial da tecnologia, mesmo que Furtado tenha considerado um fator determinante no processo de emergência do subdesenvolvimento, Street (baseado em Ayres) ofereceu um entendimento muito mais distinto e sofisticado de sua natureza, papel e onipresença em uma 'cultura baseada em tecnologia'.

'Tecnologia' é um termo tão vasto que parece uma abstração e, assim, uma força misteriosa disponível apenas aos destinados. Essa concepç̃o tem dado frequentemente aos latino americanos a sensação de uma inferioridade irremediável, frente ao esmagador domínio tecnológico de países mais avançados.

Tecnologia, como um todo, é uma maneira distinta de pensar e de agir e inclui novos modelos de organização social e habilidades de administrativas, as quais enfatizam a eficiência operacional. A absorção de tecnologia em culturas de países menos desenvolvidos deve, portanto, proceder em diversos níveis mais ou menos simultaneamente (Street 1967: 59).

Institucionalistas argumentaram continuamente que estruturas institucionais estatais repressivas e antiquadas eram, muito provavelmente, a causa primária dos fatores de perpetuação das condições de subdesenvolvimento, mesmo que tenha sido o sistema colonial que originalmente tenha cunhado estas estruturas institucionais. Portanto fatores internos deviam ser colocados no mesmo plano de análise que os obstáculos externos do desenvolvimento (Street 1987: 1881-1882). Este ponto foi perdido na corrida para construir a análise de dependência a partir da metade da década de 60 , mas não para Furtado - provavelmente devido à sua preferência metodológica por uma economia política contextualizada historicamente.

Sem referência específica às publicações de Furtado, Sunkel - um dos economistas lendários da CEPAL - reconheceu abertamente que houve uma "troca desigual" entre institucionalistas e estruturalistas e que estes "não fizeram anteriormente sua lição de casa com respeito ao institucionalismo". Não obstante, no início do ano de 1952 um argentino (Santiago Macario), um dos estudantes de Ayres, publicou "uma excelente introdução ao institucionalismo" e posteriormente trabalhou dentro da CEPAL (Sunkel 1990: 29). Sunkel então argumentou que devido ao fato do estruturalismo ter sido desafiado na América Latina pelos neoclássicos e pelos Marxistas "por um longo tempo pareceu não haver necessidade de nenhum aliado" - um comentário que não faz sentido de maneira alguma (Sunkel 1990: 32).

\section{Duas observações conclusivas}

Conforme já anteriormente discutido pelo autor (na análise do trabalho de Prebisch), ao examinar a economia política estruturalista da América Latina, detecta-se "mais do que um traço" de análise neoclássica:

Revista de Economia, v. 40, n. 3 (ano 38), p. 7-27, set/dez. 2014. Editora UFPR 
Prebisch foi muito franco sobre sua admiração à economia neoclássica no passado. Enquanto ele manteve que foi subsequentemente capaz de reformular seus pontos de vista, ainda é debatível o quão longe ele ... se distanci[ou] da análise neoclássica. Dentro dos tópicos que ele escolheu para analisar - da maneira que ele e muitos de seus colegas [da CEPAL] trataram as análises, e na maneira ampla de problemas e elementos que [a CEPAL] tratou como exógenos - há mais do que um certo cheiro de neoclassicismo. Nem ele nem a maioria dos economistas [da CEPAL] engajaram-se em um ataque frontal à teoria neoclássica. Muito menos, ainda, pareceu serem familiares com o amplo conjunto de trabalhos, particularmente derivados da escola institucionalista, que, por sua vez, poderiam ter suportado precisamente este ataque... e dispensando com a teoria de vantagens comparativas e alguns outros elementos da teoria neoclássica não constituem, propriamente, um novo paradigma da análise econômica (Cypher 1990: 43-44).

Esta crítica poderia igualmente ser aplicada, se não ainda mais, à obra de Furtado.

Por outro lado, Furtado foi na essência do arquétipo do 'intelectual orgânico' de Gramsci - dedicado, criativo, disciplinado, articulado, estratégico e erudito. Sua liderança trouxe resultados duradouros em termos da criação de um projeto nacional de desenvolvimento viável. Isso foi particularmente perceptível durante os mandatos presidenciais de Kubitschek (1956-1961) Quadros (1961) e Goulart (1961-1964) quando, como um conselheiro chave da presidência, ocupou uma série de cargos governamentais de alto nível, moldando a política de desenvolvimento. Ele foi capaz de renovar esse papel através de sua influência sobre os formuladores de política que, informados e inspirados pela análise Furtadiana, atuaram nas administrações neodesenvolvimentistas de Lula da Silva (2002-2010) e de Rousseff (2011-2014).

\section{Referências}

Alavi, H. 1982. "State and Class under Peripheral Capitalism" In Sociology of 'Developing Societies', H. Alavi and T. Shanin (eds.) New York: Monthly Review Press: 289-307.

Baer, W. 2001. The Brazilian Economy. Westport, CT: Praeger.

Baran, N. 2014. "The Baran-Sweezy Letters Project." Monthly Review 65(10): 30-48. Bértola, L. and J. Ocampo. 2012. The Economic Development of Latin America since Independence. Oxford: Oxford University Press.

Blankenburg, S., J. Palma and F. Tregenna. 2008. "Structuralism.” In The New Palgrave Dictionary of Economics Online, $2 d$ Ed. S. Durlauf and L. Blume (eds). Houndmills, England: Palgrave Macmillan: 1-9. http://www.dictionaryofeconomics. com.proxy.lib.sfu.ca/article?id=pde2008 S000312

Boianovsky, M. 2008. "A View from the Tropics: Celso Furtado and the Theory of Economic Development in the 1950s." Textos para Discussão, TD 247, Universidade Federal Fluminense, Brasil (outubro): 1-55.

. 2014. "Between Lévi-Strauss and Braudel: Furtado and the Historical-Structural Method in Latin American Political Economy.” (February): 1-37. Available at SSRN: http://ssrn.com/abstract $=2392867$

Bresser-Pereira, L. 2007. "Method and Passion in Celso Furtado.” In E. Pérez and M. Vernengo (eds.) Ideas, Policies and Economic Development in the Americas. London: Routledge: 9-30.

2011. "An Account of New Developmentalism and its Structuralist Macroeconomics." Revista de Economia Política 31, no. 3 (July-September): 493-502.

Cardoso, F. H. 2005. "Portrait of a Public Intellectual" Focus (April): 3-5. Brasilia: UNDP International Poverty Centre (IPC).

Corsi F. e J. Camargo (Organizadores). 2010. Celso Furtado: os desafios do desenvolvimento. São Paulo: Editora Cultura Acadêmica.

Cypher, J. 1979. "The Internationalization of Capital and the Transformation of Social Formations," Review of Radical Political Economics, V. 11, no. 4 (winter): 33-49.

1990. "Latin American Structuralist Economics: An Evaluation, Critique and Reformulation," in Progress towards Development in Latin America: From Prebisch to Technological Autonomy, J. Dietz and D. James (eds.) Boulder, Co.: Lynne Rienner: 41-65.

. 2009. "On the Income Gap Between Nations: Was Veblen the First Development Economist?," Journal of Economic Issues XLII, no. 2: 361-370.

2012. "Veblen y el origen de la hipótesis del Catching-Up," Revista Problemas del Desarrollo 43, (abril-junio): 9-26.

de Araújo, T., J. Macambira e S. Teixeira (organizadoes). 2009. 50 anos de Formação Econômica do Brasil. Rio de Janeiro: IPEA.

Eatwell, J., M. Millgate and P. Newman. 1989. The New Palgrave: Economic Development. New York: W.W. Norton.

Font, M. 2010. Coffee and Transformation in São Paulo, Brazil. Lanham, MD: 
CYPHER, J.M. As Origens da teoria desenvolvimentista: A economia politica ... Lexington Books.

Furtado, C. 1958. "Capital Formation and Economic Development" in A. Agarwala and P. Singh (eds) The Economics of Underdevelopment. New York: Oxford University Press: 309-340. 526-535.

1963. "Brazil: What kind of Revolution?" Foreign Affairs 41, no.3:

1964. Development and Underdevelopment. Berkeley, CA: University of California Press.

. 1970. Obstacles to Development. New York: Doubleday \& Company.

1971. The Economic Growth of Brazil: A Survey from Colonial to Modern Times. Berkeley, CA: University of California Press.

. 1983. Accumulation and Development. New York: St. Martin's Press.

. 1987. “Underdevelopment: to Conform or Reform." In Pioneers in Development, second series, G. Meier (ed.) Oxford: Oxford University Press: 203-227.

Guillén, A. y G. Vidal. 2008. Celso Furtado. Madrid: Agencia Española de Cooperación Internacional para el Desarrollo.

Harris, D. 1975. "The Theory of Economic Growth: A Critique and Reformulation, American Economic Review 65, no.2 (May): 329-337.

Heilbroner, R. and W. Millberg. 1995. The Crisis of Vision in Modern Economic Thought. Cambridge: Cambridge University Press.

Herrera, R. 2006. “The 'New' Development Economics” Monthly Review 58 no. 1 (May): 38-50.

Hodgson, G. 2001. How Economics Forgot History. London: Routledge.

Jomo K. S. and E. Reinart. 2005. The Origins of Development Economics. London: Zed.

Junker, L. 1967. "Capital Accumulation, Savings-Centered Theory and Economic Development”, Journal of Economic Issues 1, no.1-2: 25-43.

Krugman, P. 1995. "The Fall and Rise of Development Economics.” In, P. Krugman, Development, Geography and Economic Theory. Cambridge: MIT Press: 1-30.

Mallorquin, C. 2005. Celso Furtado: um retrato intelectual. Rio de Janeiro: Contraponto.

Miroswki, P. 2013. Never Let a Serious Crisis go to Waste. London: Verso.

Myint, H. 1958. The "classical theory" of international trade and the underdeveloped countries." Economic Journal. 68 (June): 317-37.

Palma, J. 1978. "Dependency: a formal theory of underdevelopment, or a methodology for the analysis of concrete situations of underdevelopment?" World Development 6, no.7-8: 881-924.

Plehewe, D. 2009. "The Origins of Neoliberal Economic Development Discourse." In P. Mirowski and D. Plehewe (eds) The Road to Mont Pèlerin. Cambridge, MA: Harvard University Press: 238-279.

Robinson, J. 1962. Economic Philosophy. London: C.A. Watts.
CYPHER, J.M. As Origens da teoria desenvolvimentista : A economia política ...

Sikkind, K. 1991. Ideas and Institutions: Developmentalism in Brazil and Argentina. Ithaca, NY: Cornell University Press.

Simon, D. (editor). 2006. Fifty Key Thinkers on Development. London: Routledge. Schumpeter, J. 1930. “Mitchell's Business Cycles," Quarterly Journal of Economics 45, no.1: 150-172.

Sombart, W. 1930. “Capitalism," in E. Seligman and A. Johnson (eds.) Encyclopedia of the Social Sciences, Vol. 3. New York: Macmillan: 195-208.

Street, J. 1967. "The Latin American 'Structuralists' and the Institutionalists: Convergence in Development Theory", Journal of Economic Issues 1, no.1-2: 44-62.

Street, J. 1987. "The Institutionalist Theory of Economic Development”, Journal of Economic Issues 21, no.4: 1861-1889.

Sunkel, O. 1990. "Structuralism, Dependency and Institutionalism: An Exploration of Common Ground and Disparities", in Progress towards Development in Latin America: From Prebisch to Technological Autonomy, J. Dietz and D. James (eds.) Boulder, Co.: Lynne Rienner: 29-40.

Tavares, M. (Organizadora). 2000. Celso Furtado e o Brasil. São Paulo: Editora Fundação Perseu Abramo.

Topik, S. 1987. A Presença do Estado na Economia Política do Brasil de 1889 a 1930. Rio de Janeiro: Editora Record. 